\title{
Book Locator: Books Manager
}

\author{
Dairelys García Rivas \\ University of Informatics Sciences, School 1, Free Solutions Center, \\ San Antonio de los Baños Highway, Km 1 1/2, \\ Torrens, Boyeros, La Habana, Cuba. CP: 19370 \\ dgrivas@uci.cu \\ http://www.uci.cu/
}

\begin{abstract}
After performing a study of digital books organizing tools, it's observed that these don't count on a multi platform integration, and those who do, don't count on the elements pursued in the investigation. It is decided then to proceed to the implementation of a book organizer software, taking an initial requirements list from the studied tools, following the guidelines of the collaborative and open source development. It has been developed to its version 4.1, which after going through different development processes, detecting mistakes and adding new functionalities that join to the requirements list, it's fully functional.
\end{abstract}

\section{Introduction}

With the increasing use of information technologies and Internet, it becomes increasingly common to use digital documents to save the information. Books are not an exception; since the growth of these technologies, people have tended to favor digital reading. This is also linked to the development of mobile devices, which allows transporting digital books. Because of this, today is much more convenient to use an Ebook Reader ${ }^{1}$, since they can carry thousands of books simultaneously in a confined space; plus the cost of digital books is much lower than physical books.

For this situation, there have been programs that allow reading these documents, in different platforms and to various formats, being most common the PDF format. These programs, however, have characteristics that prevent people working with them on multiple operating systems. Taking into account the characteristics of these applications, summarized in Table 1: Comparison of locating books programs, will be possible to decide the most appropriate program for working on multiple platforms.

\subsection{Known Results}

The intended result is based on a layered architecture, in this case two layers. It uses a presentation layer to handle all the elements involved in the generation of system views (Add, Delete, Advanced) and the warning and error messages. The other layer

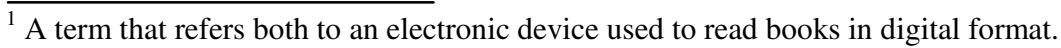

L. Corral et al. (Eds.): OSS 2014, IFIP AICT 427, pp. 230-231, 2014.

(C) IFIP International Federation for Information Processing 2014
} 
Table 1. Comparing books locating programs

\begin{tabular}{|c|c|c|c|c|}
\hline Name & Language & Platform & Special features & $\begin{array}{l}\text { Supported } \\
\text { formats }\end{array}$ \\
\hline mCatalog & English & Windows & - & All \\
\hline Alexandria & English & Linux & $\begin{array}{l}\text { Used mainly in Ubuntu, gets } \\
\text { broken sometimes }\end{array}$ & All \\
\hline Calibre & Spanish & $\begin{array}{l}\text { Linux, } \\
\text { Windows, } \\
\text { OS X }\end{array}$ & Disorganized graphic interface & All \\
\hline FBReader & $\begin{array}{l}\text { Spanish, } \\
\text { English }\end{array}$ & $\begin{array}{l}\text { Linux, } \\
\text { Windows }\end{array}$ & $\begin{array}{l}\text { Mainly designed for mobile } \\
\text { devices }\end{array}$ & $\begin{array}{l}\text { Epub, html, mobi, } \\
\text { palmDoc, zTxt }\end{array}$ \\
\hline Tellico & $\begin{array}{l}\text { Spanish, } \\
\text { English }\end{array}$ & $\begin{array}{l}\text { Linux } \\
(\mathrm{KDE})\end{array}$ & $\begin{array}{l}\text { Can't work properly in Ubuntu } \\
\text { and with GTK interfaces }\end{array}$ & All \\
\hline
\end{tabular}

used focuses on controlling access to data, validating the data before inserting it into the database and also performs queries to it, returning the results to the presentation layer.

In the main menu, there are available the options "Add book", "Delete book", "Edit book", "Advanced Search" and "Exit". The latter option terminates the application execution. In the "DB" menu are the database management options (" Create new BD", "Insert / Remove Language", "Insert / Remove Format" , "Insert / Remove genre") and in the "Utilities" menu are other utilities that the user might need ("Amount of read books", "To read books list", "Genre / Format / Language most read" and "Credits").

The interface also has a tab panel, where you can find all the books inserted, sorted in alphabetical order or by the author who wrote it. When double-clicked on the author's name, the names of the books he has written will be displayed. At the top of the window you there is a search by book name or by the name of the author who wrote it; in each case the results are shown in the panel tab. On the right side you can see the book information once you have selected in the left tab. In the bottom of the window there is a text element to be updated with interesting facts the author, as the total number of books out there, or how many books he has written an author if you select it on your tab.

The program has been tested by a group of developers of the Operating Systems Department in Cesol Center, Faculty 1. They have positive opinions regarding its functionality and support multiple platforms. The views on this have varied depending on the personal tastes of the users and the features that they want to have in a program. These recommendations have been reported to be taken into account for future releases, and it has been proposed to be inserted in the repository of the Cuban GNU / Linux distribution, Nova. 